\title{
ANALISA AERODINAMIKA BODI KENDARAAN MATARAM PROTO DIESEL DENGAN ANSYS 15.0
}

\author{
I Gusti Gde Badrawada ${ }^{1)}$, Adi Purwanto ${ }^{2)}$, Firlanda Edo $\mathbf{R}^{3)}$. \\ ${ }^{1,2,3)}$ Jurusan Teknik Mesin, Fakultas Teknologi Industri, IST AKPRIND Yogyakarta \\ ${ }^{1)}$ email : goesti@akprind.ac.id \\ 2)email : addidaiya47@gmail.com \\ Jl. Kalisahak no 28, Komplek Balapan, Yogyakarta
}

\begin{abstract}
The goal of this research was to find out the aerodynamic body design of Mataram Proto. Using Solidwork 2015 for modeling the body and Ansys 2015 for numerical simulation were the main tools of this research. The body was drawn with scale 1: 1 and then imported into Ansys 2015 for meshing. The unstructure meshes were used in this research. After those, using Ansys 2015 , the numerical simulation were conducted with viscous model $\kappa-\varepsilon$ with realizable type. The result of this research were the average drag coeficient of the original Mataram Proto body was 0,17 and its average lift coeficient was 0,17. For the modification Mataram Proto body, the average drag coeficient was 0,06 and 0,13 for average lift coeficient. These proved that the modification Mataran Proto body was more aerodynamic.
\end{abstract}

Keywords : Coeficient drag, Coeficient lift, Ansys 15.0, Aerodynamic, Streamline

\begin{abstract}
ABSTRAK
Penelitian ini bertujuan untuk menghasilkan rancangan kendaraan prototype yang aerodinamis. Dengan menggunakan Software Solidworks 2015 untuk pembuatan geometri dan Ansys 15.0 digunakan untuk simulasi computional fluid dynamics. Dalam simulasi yang dilakukan kendaraan yang diuji menggunakan skala 1:1 dengan diasumsi dengan kondisi sebenarnya. Dari simulasi yang dilakukan adalah untuk mendapatkan hasil koefisien drag dan koefisien lift. Pada Mataram Proto asal, hasil rata-rata dari koefisien drag adalah 0,17 dan koefisien lift 0,17 . Sedangkan pada proto modifikasi rata-rata koefisien drag adalah 0,06 dan koefisien lift adalah 0,13. Dari hasil koefisien drag dan koefisien lift yang didapat memberikan kesimpulan bahwa Mataram Proto Modifikasi lebih Aerodinamis dibandingkan Mataram Proto asal.
\end{abstract}

Kata kunci : Koefisien drag, Koefisien lift, Ansys 15.0, Aerodinamika, Streamline.

\section{PENDAHULUAN}

Kendaran Mataram Proto Diesel ini dirancang untuk mengikuti Kontes Mobil Hemat Energi (KMHE) dan Shell Eco Marathon Asia (SEMA). Didalam kompetisi ini mahasiswa dituntut untuk menciptakan kendaraan yang hemat bahan bakar. Bentuk bodi kendaraan merupakan salah satu dari berbagai aspek (engine, transmisi, kemudi, suspensi, rem, kelistrikan, dan estetika) yang mempengaruhi performa sebuah kendaraan. Bentuk bodi kendaraan berkaitan erat dengan beban aerodinamika.
Macam beban aerodinamika dikelompokan menjadi 3 yaitu drag force, lift force dan side force. Drag force ini adalah gaya yang sifatnya menghambat arah laju kendaraan. Lift force adalah gaya yang sifatnya mengangkat kendaraan side force adalah gaya yang sifatnya mendorong kendaraan kesamping. Drag force, lift force dan side force dipengaruhi oleh bentuk kontur bodi kendaraan, dimensi kendaraan dan kecepatan laju kendaraan.

Bentuk bodi kendaraan yang aerodinamis dapat berpengaruh pada berkurangnya pemakaian bahan bakar serta 
meminimalisir gaya-gaya yang menghambat laju kendaraan. Untuk menghasilkan bodi kendaraan yang aerodinamis dapat dilakukan dengan berbagai macam hal diantaranya dengan menggunakan program yang berbasis komputasi dinamika (CFD). Penggunaan progam CFD memiliki berbagai keuntungan diantaranya data yang dihasilkan sangat akurat serta biaya yang dibutuhkan tidak terlalu besar.

\section{TINJAUAN PUSTAKA}

Hambatan aerodinamik merupakan gaya seret yang bekerja parallel terhadap arah aliran. Gaya hambat atau yang disebut drag ini merupakan gaya yang menahan gerak benda. Secara umum gaya hambat ini terjadi akibat perbedaan tekanan antara bagian depan dan belakang benda.

Besarnya gaya hambat aerodinamik dapat diformulasikan :

$$
F_{D}=C_{D} \cdot \frac{\rho}{2} \cdot A_{F} \cdot V^{2}
$$

Keterangan :

$F_{D}=$ Gaya hambat $(\mathrm{N})$

$C_{D}=$ Koefisien hambatan plat

$\rho=$ Massa jenis fluida $\left(\mathrm{kg} / \mathrm{m}^{3}\right)$

$A_{F}=$ Luas daerah frontal $\left(\mathrm{m}^{2}\right)$

$\mathrm{V}=$ Kecepatan aliran fluida $(\mathrm{m} / \mathrm{s})$

Menurut hukum kontinuitas, semakin dekat suatu profil bergerak diatas tanah kecepatan aliran udara di antara profil dan tanah akan semakin tinggi dengan adanya pengecilan luasan, sehingga tekanan yang dihasilkan akan semakin mengecil.

Tetapi pada kondisi real, dimana aliran udara memiliki viskositas maka pada jarak ground clearance yang sangat kecil akan terbentuk boundary layer pada bagian bawah mobil dan boundary layer pada tanah. Boundary layer ini akan mengadakan interaksi satu sama lain sehingga akan memperlambat kecepatan aliran tekanan yang dihasilkan semakin besar.

Pada mulanya gaya angkat ini tidak terlalu diperhatikan karena kecepatan tidak menimbulkan gaya angkat yang cukup berat, tetapi dengan kemajuan teknologi yang berkembang pesat dimana kecepatan kencaraan yang semakin tinggi dapat menimbulkan masalah dalam hal stabilitas dan respon kendaraan. Semakin cepat kendaraan melaju semakin sulit dikendalikan.
Salah satu cara untuk mengendalikan stabilitas dan respon kendaraan adalah dengan cara memperkecil gaya angkat yang ditimbulkan.

Besarnya gaya angkat ini memiliki formulasi :

$$
F_{L}=C_{L} \cdot \frac{\rho}{2} \cdot A_{F} \cdot V^{2}
$$

$$
\begin{aligned}
& \text { Keterangan : } \\
& F_{L}=\text { Gaya angkat }(\mathrm{N}) \\
& C_{L}=\text { Koefisien angkat pada plat } \\
& \rho=\text { Massa jenis fluida }\left(\mathrm{kg} / \mathrm{m}^{3}\right) \\
& A_{F}=\text { Luas daerah frontal }\left(\mathrm{m}^{2}\right) \\
& V=\operatorname{Kecepatan} \text { kendaraan }(\mathrm{m} / \mathrm{s})
\end{aligned}
$$

\section{METODE PENELITIAN}

\section{A. Pembuatan Desain}

Desain geometri bodi kendaraan menggunakan Solidworks 2015. Model bodi kendaraan prototype yang dibuat hanya permukaan bodi. Selanjutnya dilakukan simulasi dengan metode computational fluid dynamics (CFD) pada Program Ansys 15.0. Desain rancangan Mataram Proto Diesel dan Proto modifikasi yang di buat dengan Solidworks 2015 dapat dilihat pada Gambar 1 dan Gambar 2.

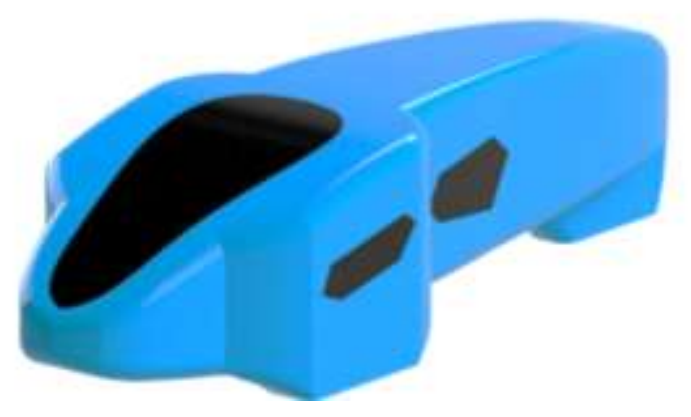

Gambar 1 Mataram Proto Diesel

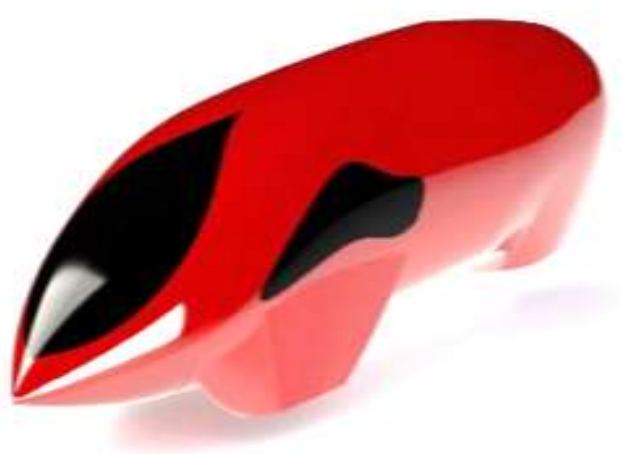

Gambar 2 Proto Modifikasi 
Langkah selanjutnya adalah melakukan import geometri pada Ansys 15.0 dengan hasil seperti pada Gambar 3 dan Gambar 4.

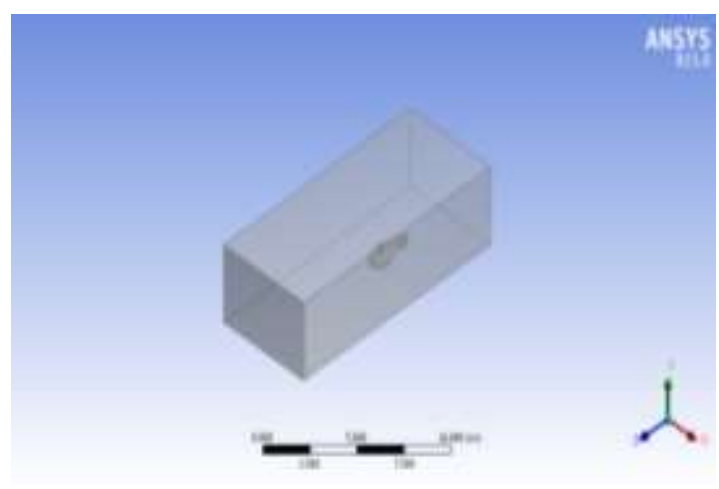

Gambar 3 Import Mataram Proto Diesel

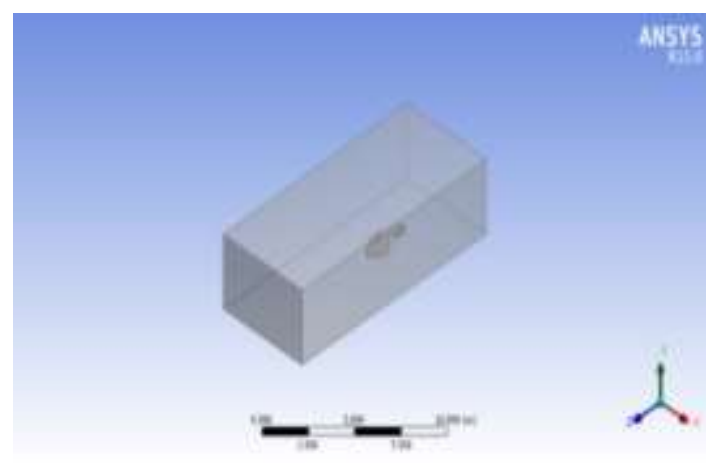

Gambar 4 Import Proto modifikasi

\section{B. Proses Meshing}

Proses meshing yang dilakukan pada Ansys ini adalah untuk membagi bagianbagian bodi kendaraan menjadi kecil untuk dilakukan simulasi.

Hasil mehing pada Mataram Proto Diesel dan Proto Modifikasi dapat dilihat pada Gambar 5 dan Gambar 6.

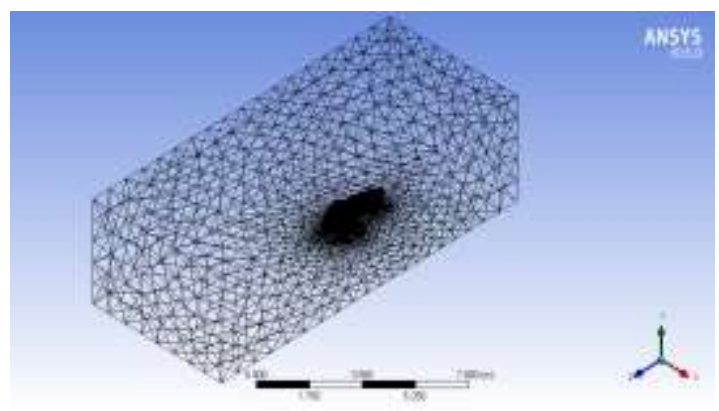

Gambar 5 Meshing Mataram Proto Diesel

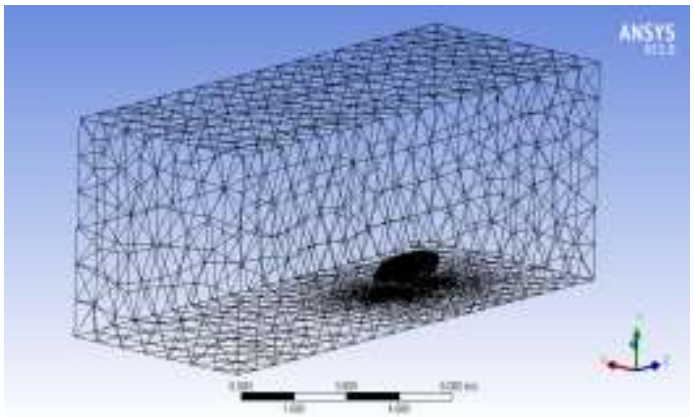

Gambar 6 Meshing Proto modifikasi

Parameter yang digunakan saat simulasi antara lain :

1) Temperatur udara $40^{\circ} \mathrm{C}$

2) Density $1,118136 \mathrm{~kg} / \mathrm{m}^{3}$

3) Viskositas dinamik $190,736 \times 10^{-7}$ $\mathrm{kg} / \mathrm{ms}$

4) Luas frontal area Mataram Proto Diesel $0,50382 \mathrm{~m}^{2}$

5) Luas frontal area Proto Modifikasi $0,334854 \mathrm{~m}^{2}$

\section{HASIL SIMULASI}

Penelitian aerodinamika dengan menggunakan Ansys 15.0-Fluent ini kecepatan yang digunakan adalah: $20 \mathrm{~km} / \mathrm{jam}$, $30 \mathrm{~km} / \mathrm{jam}, 40 \mathrm{~km} / \mathrm{jam}, 50 \mathrm{~km} / \mathrm{jam}$ dan 60 $\mathrm{km} / \mathrm{jam}$. Dengan hasil dari koefisien drag dapat dilihat pada Tabel 1 dan Grafik 1, sedangkan perbandingan hasil dari koefisien lift dapat dilihat pada Tabel 2 dan Grafik 2.

Tabel 1 Hasil koefisien drag

\begin{tabular}{|l|l|l|l|l|l|l|}
\hline \multirow{2}{*}{$\begin{array}{l}\text { Uecepatan } \\
\text { Udara }(\mathrm{m} / \mathrm{s})\end{array}$} & $\begin{array}{l}\text { Mataram Proto Diesel } \\
\text { Koefiesen } \\
\text { drag (Cd) }\end{array}$ & Iterasi & Time & $\begin{array}{l}\text { Koefiesen drag } \\
(\mathrm{Cd})\end{array}$ & Iterasi & Time \\
\hline 5.55 & 0.1763 & 50 & 0 & 0.0709 & 49 & $0: 00-09$ \\
\hline 8.33 & 0.1713 & 50 & 0 & 0.0692 & 49 & $0-00: 10$ \\
\hline 11.11 & 0.1681 & 50 & 0 & 0.068 & 49 & $0-00-10$ \\
\hline 13.88 & 0.1659 & 50 & 0 & 0.067 & 49 & $0: 00: 10$ \\
\hline 16.66 & 0.1642 & 50 & 0 & 0.0664 & 49 & $0: 00: 10$ \\
\hline
\end{tabular}




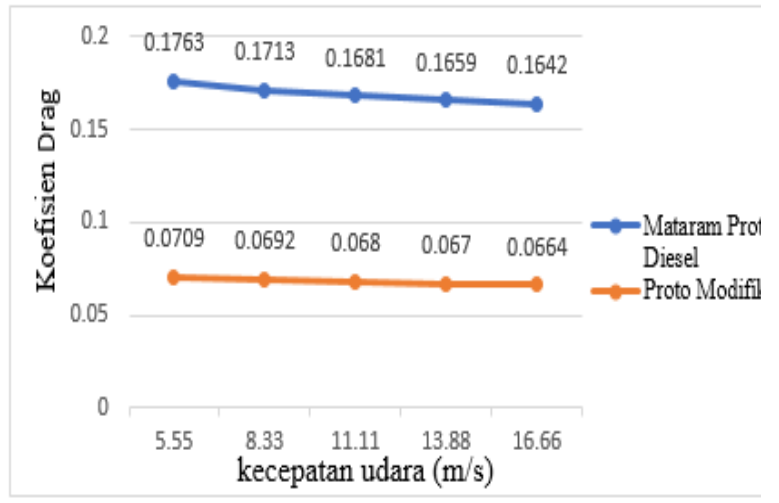

Grafik 1 Perbandingan koefisien drag

Dari hasil simulasi koefisien drag dapat dilihat bahwa proto modifikasi lebih kecil koefisien dragnya yaitu dengan nilai rata-rata 0.06 sedangkan pada mataram proto diesel lebih besar yaitu 0.17 koefisien dragnya. Artinya hambatan udara pada Proto modifikasi lebih kecil.

Tabel 2 Hasil koefisien lift

\begin{tabular}{|c|c|c|c|c|c|c|}
\hline \multirow{2}{*}{$\begin{array}{l}\text { Kecepatan } \\
\text { Udara (m/s) }\end{array}$} & \multicolumn{3}{|c|}{ Mataram Proto Diesel } & \multicolumn{3}{|c|}{ Proto Modifikasi } \\
\hline & $\begin{array}{l}\text { Koefiesen } \\
\text { lift (CI) }\end{array}$ & Iterasi & Time & $\begin{array}{l}\text { Koefiesen } \\
\text { lift (CI) }\end{array}$ & Iterasi & Time \\
\hline 5.55 & 0.1736 & 50 & 0 & 0.1319 & 49 & $0: 00: 09$ \\
\hline 8.33 & 0.1724 & 50 & 0 & 0.1321 & 49 & $0: 00: 10$ \\
\hline 11.11 & 0.1714 & 50 & 0 & 0.1321 & 49 & $0: 00: 10$ \\
\hline 13.88 & 0.1707 & 50 & 0 & 0.1321 & 49 & $0: 00: 10$ \\
\hline 16.66 & 0.17 & 50 & 0 & 0.1321 & 49 & $0: 00: 10$ \\
\hline
\end{tabular}

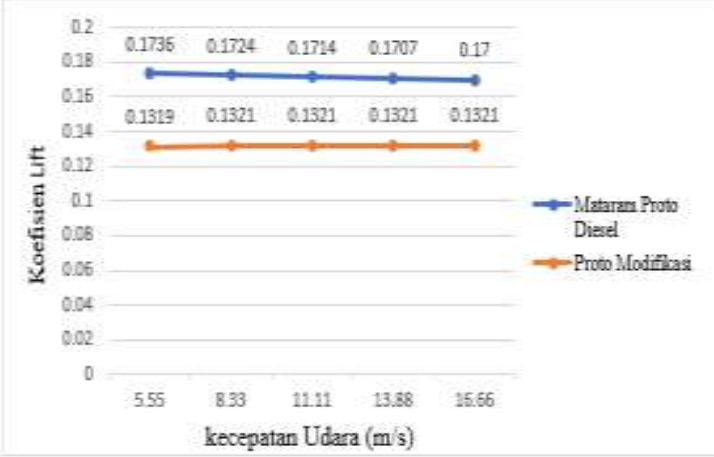

Grafik 2 Perbandingan koefisien lift

Dari tabel diatas dapat dilihat bahwa nilai koefisient lift force mengalami peningkatan walau pun kecil seiring bertambahnya kecepatan aliran udara untuk kendaran Mataram Proto nilai koefisen ratarata adalah yaitu sebesar 0.17 sedangkan untuk Proto Modifikasi dapat dilihat bahwa nilai koefisient lift force mengalami kenaikan walaupun kecil seiring bertambahnya kecepatan aliran udara dimana besar rata-rata koefisien lift-nya 0.13 .

Dari hasil simulasi dapat juga dilihat aliran udara disekitar kedua bodi kendaraan yang dapat dilihat pada Gambar 7 dan Gambar 8.

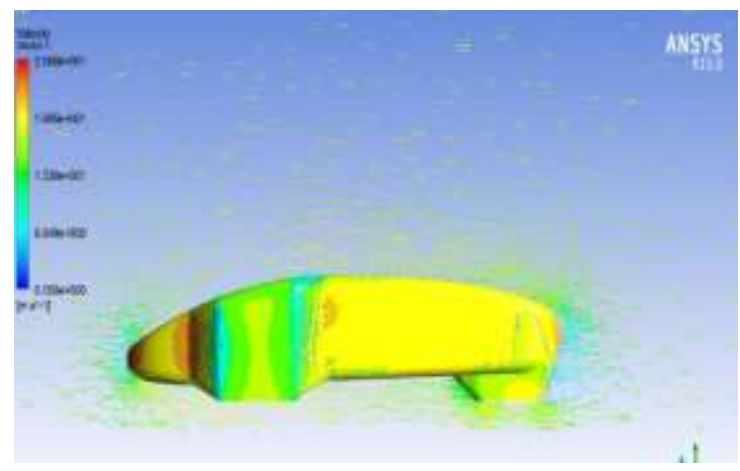

Gambar 7 Aliran udara disekitar bodi Mataram Proto Diesel

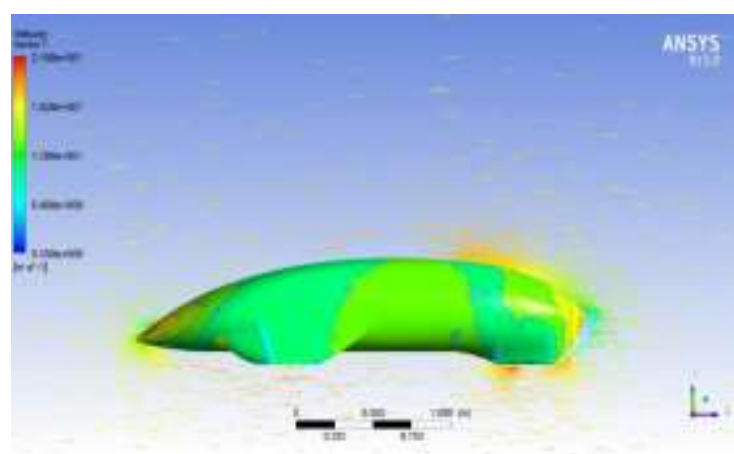

Gambar 8 Aliran udara disekitar bodi Proto modifikasi

Dari Gambar 7 dan Gambar 8 dapat dilihat warna aliran udara bagian depan berwarna biru yang berarti kecepatannya nol, berarti pada bagan depan bodi yang terjadi pada Mataram Proto Diesel terdapat vortex, hal ini mengakibatkan nilai koefisien drag meningkat, sedangkan pada Proto modifikasi aliran yang terjadi disekitar bodi berwarna dominan kuning dan bagian depan terdapat warna hijau terdapat aliran udara yang tidak terhambat.

Dapat juga ditampilkan contour pressure disekitar bodi kendaraan yang ditunjukkan pada Gambar 9 dan Gambar 10. 


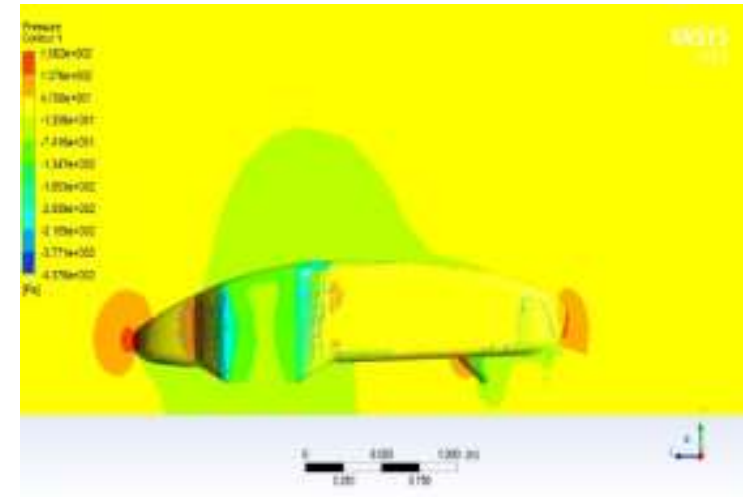

Gambar 9 Pressure bodi Mataram Proto Diesel

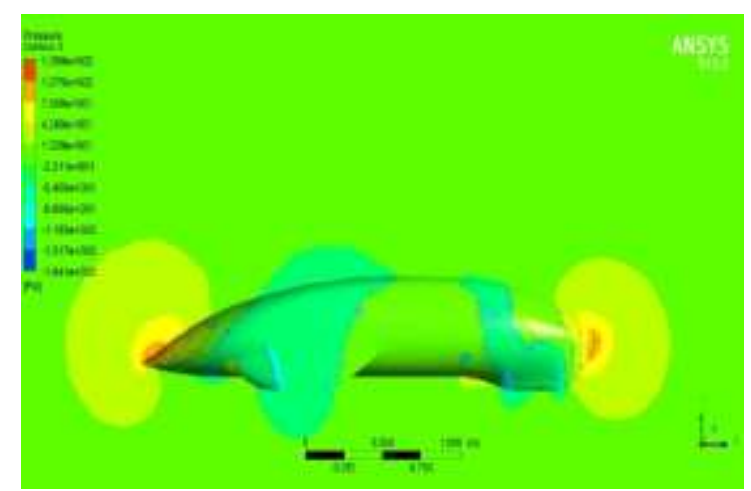

Gambar 10 Pressure bodi Proto modifikasi

Dari Gambar 9 dan Gambar 10 yang menunjukkan pressure pada Mataram Proto Diesel dan Proto modifikasi dapat dilihat bahwa tekanan terbesar pada Mataram Proto Diesel dan Proto modifikasi terdapat pada bagian depan kendaraan dan belakang kendaraan ditunjukkan dengan warna merah, namun ada yang berbeda pada bagian bodi untuk roda depan, dimana pada Mataram Proto Diesel lebih besar tekanannya, karena bentuk dari bodi itu sendiri hal ini ditunjukan dengan warna merah pada bodi tersebut. Boundary layer yang terjadi pada Mataram Proto diesel akan lebih tebal dibandingkan dengan Proto modifikasi karena tekanan pada kendaraan yang lebih besar dengan ditunjukkan dengan warna merah yang mengakibatkan aliran udara terhambat.

Selanjutnya adalah aliran streamline disekitar bodi kendaraan yang ditunjukkan Gambar 11 dan Gambar 12.

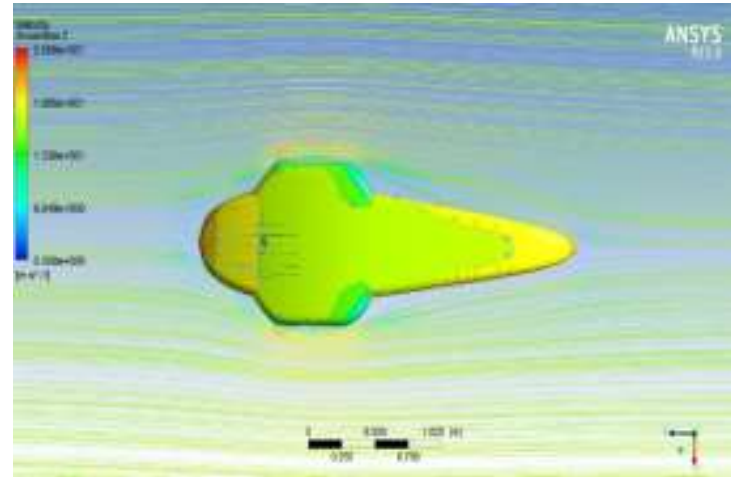

Gambar 11 Streamline bodi Mataram Proto Diesel

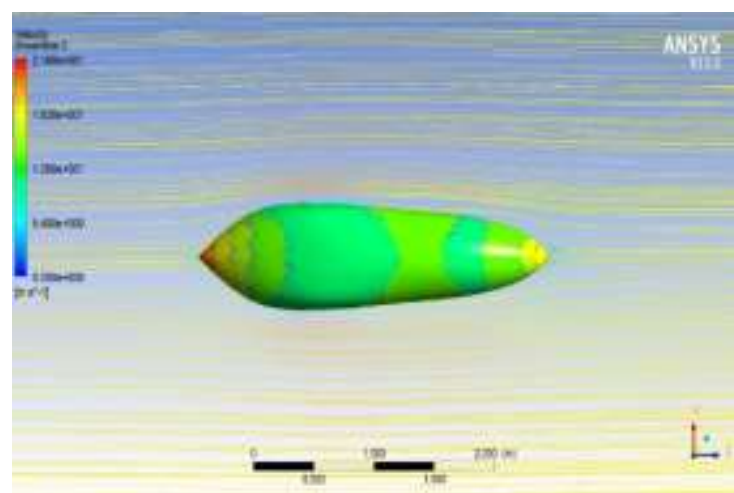

Gambar 12 Streamline bodi Proto modifikasi

Dari Gambar 11 dan Gambar 12 yang menunjukkan pressure pada Mataram Proto Diesel dan Proto modifikasi dapat dilihat pada Mataram Proto Diesel pada bagian roda depan dan belakang aliran streamline nya lebih terhambat dibandingkan dengan Proto modifikasi. Pada bagian depan terlihat Proto modifikasi alirannya lebih streamline dibandingkan dengan Mataram Proto Diesel.

\section{KESIMPULAN}

1) Koefisien drag yang diperoleh saat simulasi pada mataram proto diesel adalah 0.17 sedangkan pada proto modifikasi lebih kecil yaitu 0.06, hasil ini telah memenuhi target yang diinginkan yaitu dibawah 0.15 .

2) Koefisien lift yang diperoleh saat simulasi pada Mataram Proto Diesel lebih besar yaitu 0.17, sedangkan pada Proto modifikasi lebih kecil yaitu 0.13 . hal ini dikarenakan tekanan udara pada Mataram Proto diesel lebih besar dibagian atas dibandingkan pada bagian bawah, sedangkan pada Proto modifikasi tekanan 
udara lebih besar pada bagian atas dibandingkan bagian bawah.

3) Perubahan bentuk yang dilakukan pada Proto modifikasi terbukti lebih baik dibandingkan dengan Mataram Proto Diesel, dimana tekanan pada area sekitar bodi Mataram Proto Diesel lebih besar dibandingkan dengan Proto modifikasi, aliran udara disekitar bodi lebih cepat Proto modifikasi dibandingkan dengan Proto Diesel. hal ini tidak terlepas dari perubahan pada bodi bagian depan yaitu pada ujung depan lebih kecil pada sudut serangnya yang membuat distribusi tekanan lebih kecil.

4) Hasil dari koefisien drag dan lift pada Proto modifikasi lebih kecil dari Mataram Proto Diesel ini berarti aerodinamika pada Proto Modifikasi lebih baik, hal ini berpengaruh pada kerja engine tidak memerlukan daya yang besar untuk menggerakan kendaraan sehingga konsumsi bahan bakar lebih irit.

\section{Daftar Pustaka}

Anderson, John D., Jr., 1986. Fundamental of aerodynamic, Mc Graw-Hill, New York.

Andri. 2012, Tekanan hidrostatik, termuat dalam web : https://mekanikafluidatm.wordpress.com /materi-kuliah/page/2/, Diakses 18 januari 2017.

Azwir, Hail. 2014. "Analisa Computional Fluid Dynamic body kendaraan Mataram Proto dengan prangkat lunak ansys fluent 14.0". Tugas Akhir Tenik Mesin, IST AKPRIND, Yogyakarta

Dieter L. Goerge., \& Schmidt C. Linda., 2009, Engineering Design, Fourth Edition, Published by McGraw-Hill Companies, New York.

Gerhart, Philip M, Gross, Richard J., \& Hochstein, John I., 1992, Fundamentals of Fluid mechanics, $2^{\text {nd }}$ ed, AddisonWesley Publishing Company., New York.

Hall, Nancy. 2015. The Lift Coefficient, termuada dalam web : https: //www.grc.nasa.gov/www/K-

12/airplane/liftco.html, diakses 9 maret 2017.

Hamidi, Abdullah., 2011, Analisa Aerodinamika Pada Permukaan Urban Concept Car SEM UI "Kalabiya" dengan CFD, Tugas Akhir Tenik Mesin, Universitas Indonesia, Depok.

Hirt, Tony. 2016, Modeling Turbulence Viscosity, termuat dalam https://www.cfd-online.com/ Wiki/Standard_k-epsilon_model \#Modeling _turbulent_viscosity, diakses 29 november 2016.

Hucho, Wofl-Heinrich., 1998, Aerodynamic of road vehicles, $4^{\text {th }}$ ed, SAE international, London.

Huda, Nurul. 2016. Analisa Aerodinamika Pada Mobil Bayu Surya Menggunakan CFD Pada Software Ansys 15.0. Tugas Akhir Teknik Mesin Universitas Muhammadiyah, Surakarta

Miliken, F, Wiliam \& Miliken, L, Douglas, 1995, Race Car Vehicle Dynamic, Volume 1, Society of Automotive Engineers, London.

Munson, Bruce R., Young, Donal F. \& Okiishi, Theodore H., 2003, Mekanika Fluida, Jilid 1, Edisi Ke 4, Alih Bahasa : Harinaldi \& Budiarso, Erlangga, Jakarta.

Norton L. Robert., 2013, Machine Design, Edition 5, Publisher Pearson Education, United States.

Prabu, Anindio 2016., Turbulensi Model K epsilon, termuat dalam web : https://anindioprabu.wordpress.com/2012/0 5/25/turbulensi-model-k-epsilon/. Diakses 3 Maret 2017.

Sarif, Lukman,. 2013, Perancangan Aerodinamika Body Mobil Sport Berbasis Komputasi Dinamik Fulid Dengan Menggunakan Program Ansys 13.0, Tugas Akhir Teknik Mesin, IST Akprind, Yogyakarta 
Siregar, Munawir Rosyadi dan Ambarita Himsar, 2012, Analisa Koefisien Drag Pada Mobil Hemat Energi "Mesin USU" Dengan Menggunakan Perangkat Lunak CFD, Jurnal e-Dinamis, Vol 3, No. 3 Desember 2012

Street, Victor L, \& Wylie E.B., 1999, Mekanika Fluida Jilid 1 \& 2 Edisi Delapan, Alih Bahas : Arko Prijono, Erlangga, Jakarta.

Wibhisono, Haryo. 2016, Permodelan Aliran Turbulence K-Epsilon, Termuat dalam web:

http://haryochi.blogspot.co.id/2016/04/perm ode lan -aliran-turbulence-k-epsilon.html/, Diakses 29 november 2016. 